\title{
Entrepreneurial Inclination: South African Youth's Mental Attitude towards starting Tourism Business
}

\author{
Ikechukwu O. Ezeuduji*, Sibusiso D. Ntshangase \\ University of Zululand, South Africa \\ EzeudujiI@unizulu.ac.za*, sdbiyela@gmail.com
}

\begin{abstract}
This study assessed the tourism entrepreneurial intention of South African youth, and the mental attitude of those who have this intention. It used questionnaire survey to gather data from 207 youth resident in Mtubatuba Local Municipality, KwaZulu-Natal Province of South Africa, to address the study objectives. Data analyses reveal that a significant percentage of the youth have tourism entrepreneurial intention. Those who perceive themselves as entrepreneurial individuals and willing to start tourism businesses in the future exhibit some distinct mindset. This mental attitude depicts these individuals to be innovative, transformational, risk takers, persistence, strong-minded, visionary, optimistic, and goal-getters. The South African Government, through its Department of Labour, need to optimize its strategic and operational plans to support these entrepreneurial youth in acquiring business education and entrepreneurial skills, to empower them realise their dreams of starting and managing their own businesses. This will help curb the high rate of unemployment in South Africa, especially among the youth.
\end{abstract}

Keywords: Entrepreneurial inclination, entrepreneurial intention, tourism entrepreneurship, youth entrepreneurship, sub-Saharan Africa

\section{Introduction}

The South African unemployment rate was $27.7 \%$ in the first quarter of 2017 . It was $26.5 \%$ in the previous quarter. This first quarter of 2017 was described as having the highest jobless rate since the first quarter of 2004. The youth unemployment rate in South Africa was 54.2\% in the third quarter of 2016 and 50.9\% in the fourth quarter of 2016. The youth unemployment rate averaged 51.54\% from 2013 to 2016 in South Africa (Trading Economics, 2017 a,b).Youth entrepreneurship therefore, will alleviate this jobless rate in South Africa, as new businesses can help create new jobs for the entrepreneurs and their future employees. South Africa, just like any other developing country, aims to build a strong economy that will become globally competitive. Previous studies posit that entrepreneurship is a vehicle that can drive any nation's economy (Chell, Spence, Perrini, \& Harris, 2016; Gree \& Thurnik, 2003; Iwu, Ezeuduji, Eresia-Eke \& Tengeh, 2016; Maziriri \& Madinga, 2016; Maziriri, Madinga \& Lose, 2017). As every nation in the world tries to decrease the unemployment levels of its youth, the youth also need to help themselves by making a practical identification of business opportunities around them and turning these into business venture. Mtubatuba Local Municipality in the KwaZulu-Natal Province of South Africa boasts Agriculture as its largest employment sector, nonetheless, there is a huge potential for expanding its tourism industry (especially the eco-tourism niche), as its natural resources include both private and public game and nature reserves, accommodation establishments, restaurants and various sporting facilities. One of this municipality's Local Economic Development objectives is "to ensure poverty alleviation, shared wealth creation, community stability and raised standards of living through formal job creation, entrepreneurial activity, and Small, Medium and Micro Enterprises (SMME) development" (Mtubatuba Municipality, 2017).

Previous researchers in sub-Saharan Africa have reported that entrepreneurship is a significant part of the solution to Africa's economic development problems (Maziriri \& Madinga, 2016; Nchu, Tengeh \& Hassan 2015; Olomi \& Sinyamule, 2009). This study argues that in as much as many African youth may desire to own their own businesses due to the benefits this may present, it is imperative for aspiring entrepreneurs to have the right motivation, the drive and the mindset to start, grow and manage businesses on the long-term. Aspiring entrepreneurs also do not necessarily need to have the financial capital to start their own businesses, but should know how to acquire the capital. As earlier mentioned, there exist tourism business opportunities for the youth of Mtubatuba Local Municipality in the KwaZulu-Natal. This study will therefore assess the tourism entrepreneurial intention of the South African youth living in this area, and the mental attitude of those youth who perceive themselves as entrepreneurial individuals. This study will further evaluate if their mindset is appropriate towards starting and sustaining these businesses. This study regards 
individuals less than 36 years as youth members. The next section explores recent and relevant literature related to this study.

\section{Literature Review}

Entrepreneurship is a driving force behind the socio-economic success of any nation (Ahmad, 2015), as it creates more jobs and reduces poverty (Chenube, Saidu, Omumu \& Omomoyesan, 2011; Olomi \& Sinyamule, 2009; Singh \& Singh, 2016). Authors such as Chenube et al. (2011) suggest that unemployment can be reduced through encouraging the development of the informal sector, where people are empowered towards becoming independent or self-employed. Minto-Coy and McNaughton (2016) allude to the fact that innovation and entrepreneurship are considered essential pillars of growth and country's ability to narrow the gap between themselves and others. Lekoko, Rankhumise and Ras (2012) posit that higher education institutions can help create a more entrepreneurial disposition among young people by instilling a clear understanding of risks, taking opportunity, as well as creating and building enterprises. Premand, Brodmann, Almeida, Grun and Barouni (2016) state that entrepreneurship education has the potential to enable youth to gain skills and create their own jobs, hence policymakers should pay attention to it. Bakare (2015) posits that youth empowerment programs should include entrepreneurial training. Hence Lekoko et al. (2012) examined the effectiveness of entrepreneurship education to empower youth's awareness of self-employment as a career option and creating business culture amongst them. They argue that entrepreneurship education program should integrate both the theoretical transfer of entrepreneurship knowledge and the practical learning experience. This study however argues that entrepreneurship education may not really spur someone with no entrepreneurship inclination to entrepreneurship action. Chenube et al. (2011) report that entrepreneurial inclination can be stimulated by a healthy education background, relevant work history, having good entrepreneurs as role models, morale-network support and professional support network. These are variables that the authors argue will result in the success of the entrepreneurial process. Therefore, entrepreneurial inclination and entrepreneurial education are two factors that support youth's entrepreneurship development (Chenube et al., 2011).

Few studies have been conducted on entrepreneurial inclination in the developing countries like South Africa (such as Ali, Topping \& Tariq, 2009; Mahmoud, Muharam \& Mas'ud, 2015; Olomi \& Sinyamule, 2009; Omerzel, 2015; Singh \& Singh, 2016). Omerzel (2015) proposes the five dimensions of entrepreneurial inclination to be risk taking, proactiveness, competitive aggressiveness, autonomy, and customer orientation. Mahmoud et al. (2015) argue that the entrepreneurial inclination is the best predictor of business venture, as it can predict the process of business creation (Krueger, Reilly \& Carsrud, 2000). Venture creation is not likely to take place without motivation (Owoseni \& Akambi, 2010). In this study, entrepreneurial inclination is viewed in terms of motivation and attitude towards starting a new business. The attitude or motivation and perceived behavioral control are described as the qualifications of entrepreneurial inclination (Singh \& Singh, 2016). Gwija, Eresia-Eke and Iwu (2014) and Iwu et al. (2016) posit that the level of entrepreneurial engagement in South Africa is very low due to a general lack of infrastructural support, lack of capital, and poor business management ability. Singh and Singh (2016) report that the entrepreneurial inclination of youth plays critical role in deciding their future entrepreneurial behaviour. Hence, entrepreneurship is receiving more attention in the area of business research (Sandhu, Sidique \& Riaz, 2011; Singh \& Singh, 2016). Singh and Singh (2016) allude that seminars, workshops and conferences are being organized often in universities and similar organizations to inform the youth about entrepreneurial programs. They (Singh \& Singh) suggest that entrepreneurial intent is a primary predictor of future entrepreneurial behavior, and Sandhu et al. (2011) report that young people who are more mature and have greater job experience will be more likely to be inclined towards entrepreneurship. Sandhu et al. (2011) outline the barriers of entrepreneurship to be aversion to stress and hard work, aversion to risk, fear of failure, lack of social networking, lack of resources, and demographic and personal factors.

The barriers faced by the youth who want to start their own businesses will be different when compared with barriers faced by existing entrepreneurs. Hence, understanding these barriers and relationships between entrepreneurial inclinations and the practicality of starting new business ventures will support policymakers in formulating new support strategies. Lengyel (2015) reports that there is a remarkable distinction between those who would like to be entrepreneurs and those who actually intend to be. The author (Lengyel) posits 
that the entrepreneurial potential means an inclination, a kind of openness, readiness to grasp a business opportunity, and not necessarily a deliberate intention to become an entrepreneur. This information is relevant as this research is concerned with entrepreneurial inclination. Previous authors (such as Burger, Mahadea \& Neil, 2004; Maziriri \& Madinga, 2016; Maziriri, Madinga \& Lose, 2017; Steenekamp, Van der Merwe \& Athayde, 2011) have reported that South African population (the youth inclusive) does not suffer from a lack of creative spirit, but from a lack of business education and entrepreneurial skills that can empower them in an enabling environment. Iwu et al. (2016) put forward that among other factors, the socioeconomic conditions and education system are the most critical factors influencing the development of entrepreneurship in the global economy. The study by Iwu et al. (2016) in South Africa, reported that there is a growing entrepreneurial inclination among the educated youth (university students), however this study will assess the tourism entrepreneurial intention of South African youth, not focusing on their level of Western education. It will also compare the youth's perceived level of their own entrepreneurial inclination and the mental attitude of those youth. The youth's mental attitude may reveal the probability of their starting and sustaining these businesses. In the next section, we will outline how we designed, generated and analysed collected data to reach study conclusions.

\section{Methodology and Design}

When the nature of research objectives requires individual and quantified responses, questionnaire survey is usually ideal to obtain information to address these research objectives Veal (2011). We used a combination of respondent-completed and interviewer-completed structured questionnaire to collect information from 207 youth of Mtubatuba Local Municipality in the KwaZulu-Natal Province of South Africa. We used interviewer-completed questionnaire method when respondents cannot complete the questionnaire in English language. When this was the case, one of the researchers who is resident in the study area translated the questionnaire in the local language, and completed the respondents' answers. We did both household survey and street survey, using simple random sampling technique, to select our respondents. The questionnaire we used has two sections: profile data and perception variables. The profile data were set as categorical variables, and the perception variables were set as ordinal variables. The perception variables include entrepreneurship 'meanings', perceptions of entrepreneurial inclinations, and enablers and barriers of starting tourism businesses (set on a 5-point Likert scale: 1 - strongly agree, to 5 - strongly disagree). These ordinal variables originate from the literature review for this paper.

We used IBM's SPSS version 24 software for statistical analyses (IBM Corporation, 2016) of the data collected. We conducted descriptive (percentage frequencies and mean scores of responses), bivariate (Mann-Whitney $\mathrm{U}$ tests) and multivariate analyses (Reliability tests). All statistical tests were done at $95 \%$ confidence interval. Due to non-normal population distributions of the ordinal variables used in measuring entrepreneurship statements (perceptions); we conducted Mann-Whitney U tests of comparing means of responses from two independent groups to verify if these are different from each other. Responses to entrepreneurship statements were compared with some respondents' profile (self-declaration as entrepreneurial individual, willingness to start own tourism business, prior entrepreneurship education, and respondents' gender). Mann-Whitney $U$ tests were conducted based on the criteria that the dependent variables have ordinal scale; the independent variables have only two groups; and normality of distribution and homogeneity of variance did not prove true in a t-test (George \& Mallary, 2003; Veal, 2011). We conducted reliability tests (multivariate analysis) to check for the level of internal consistencies of the variables we used to explain different factors (perceptions of entrepreneurship 'meanings', perceptions of entrepreneurial inclinations, and enablers and barriers of starting tourism businesses). Based on literature (George \& Mallery, 2003), the use of Cronbach's Alpha coefficient of between 0.5 and 0.7 is acceptable in social science research, to explain adequate consistency of variables. Nonetheless, Tavakol and Dennick (2011) posit that low Cronbach's Alpha score may occur if there is a weak interrelationship among questionnaire variables that are used in the analysis, or when few variables are being used to explain a particular dimension. The reliability test results in this study show that we used variables that are internally consistent to measure study factors. We present results of the data analyses and discuss findings in the next section. 


\section{Results and Discussion}

The results presented in Table 1 show that there is a balanced distribution between male and female respondents in this survey. The study show that about $64 \%$ of the respondents are relatively young, between the ages of 18 and 25 .

Table 1: Youth profile $(\mathrm{N}=207)$

\begin{tabular}{lll} 
Variable & Category & Frequency (\%) \\
\hline 1.1 Gender & Male & 50.5 \\
& Female & 49.5 \\
1.2 Age group & $18-25$ & 64.0 \\
& $26-30$ & 23.3 \\
1.3 Highest level of education attained & $31-35$ & 12.7 \\
& No western education & 3.4 \\
& Primary education & 4.9 \\
1.4 Are you South African? & Secondary education & 54.4 \\
& Tertiary education & 37.3 \\
1.5 Did you study any Business Management or & Yes & 96.1 \\
Entrepreneurship course/programme? & No & 3.9 \\
1.6 Would you want to start your own tourism & Yes & 54.8 \\
business in the future? & No & 45.2 \\
1.7 Do you think you are an entrepreneurial & Yes & 77.1 \\
individual? & No & 22.9 \\
1.8 Starting tourism business can change young & Yes & 65.3 \\
people's life & No & 34.7 \\
& & 86.5 \\
\hline
\end{tabular}

The results showing that about $92 \%$ of the respondents have secondary or tertiary education, reveal that the general educational level of the South African youth population living in the study area is not a significant barrier for them to venture into entrepreneurship, especially as about $55 \%$ of them indicated that they have had some business management or entrepreneurship education. This study has some good news as about $77 \%$ of the surveyed sample declared their intention to start their own businesses in the future, and about $65 \%$ of these respondents perceive themselves as entrepreneurial individuals. Much of the youth surveyed (about 87\%) agree that entrepreneurship can make a positive impact in their lives. These results support Iwu et al. (2016) earlier finding that there is an increasing level of entrepreneurial intention among South African youth. This study however argues that the declared entrepreneurial intention of these youth may not turn into actually starting and managing their businesses. Some of them may start businesses and eventually become unsuccessful due to personal factors or external factors found in their environment. However, we posit that for a developing economy like South Africa, these results can be viewed as promising, as much entrepreneurship interest exists among the youth surveyed.

The next stage of data analysis compared relevant respondents' entrepreneurial profile (gender, perception of self as entrepreneurial, prior entrepreneurship education, and willingness to start own tourism business in the future) with entrepreneurship statements. Bivariate analysis (Table 2) reveal that much of the youth members who declare themselves to be entrepreneurial individuals(and mostly want to start tourism businesses) perceive entrepreneurship 'meanings' to be those of invention, taking risk, organising and managing own business, and increasing capital and wealth. Based on their level of agreements to the entrepreneurial inclination's statements, they mostly 'are constantly on the lookout for new ways to improve their lives', 'feel driven to make a difference in their community, and maybe in the world', 'feel they are powerful forces for constructive change', 'make something happen, against all odds, if they believe in it', 'are always looking for better ways to do things', 'tackle their problems head-on', and 'can spot a good opportunity long before others can'; more than those who think they are not entrepreneurial individuals. Those who want to start their own tourism businesses in the future see themselves as 'fixers of problems', 'those who can make things happen', and 'able to help out people in trouble'. More male than female respondents also made similar reports on themselves, however based on the overall results (responses to only few variables show 
statistical difference based on gender), it cannot be generalized that male respondents have more statistically significant entrepreneurial inclination than females. Male respondents however, show more persistent and supportive personalities.

Table 2: Entrepreneurship statements compared with 'entrepreneurial profile' $(\mathrm{N}=207)$

\begin{tabular}{|c|c|c|}
\hline $\begin{array}{l}\text { Perceptions of entrepreneurship } \\
\text { 'meanings' b }\end{array}$ & Mean & Compared with 'entrepreneurial profile' a \\
\hline $\begin{array}{l}2.1 \text { Being an entrepreneur means creating } \\
\text { an own business }\end{array}$ & 1.77 & N.S \\
\hline $\begin{array}{l}2.2 \text { Being an entrepreneur means } \\
\text { organising and managing own business }\end{array}$ & 1.93 & $\begin{array}{l}\text { **Those who think they are entrepreneurial }^{\text {individuals agree more; }} \\
\text { ***Those with prior entrepreneurship education } \\
\text { agree more; } \\
\text { **Those want to start own tourism business in } \\
\text { the future agree more. }\end{array}$ \\
\hline $\begin{array}{l}2.3 \text { Being an entrepreneur means taking } \\
\text { risks }\end{array}$ & 2.44 & $\begin{array}{l}\text { ***Those who think they are entrepreneurial } \\
\text { individuals agree more; } \\
\text { **Those with prior entrepreneurship education } \\
\text { agree more. }\end{array}$ \\
\hline $\begin{array}{l}2.4 \text { Money is the only thing that an } \\
\text { entrepreneur needs }\end{array}$ & 2.68 & N.S \\
\hline 2.5 An entrepreneur is an inventor & 2.34 & $\begin{array}{l}{ }^{* *} \text { Those who think they are entrepreneurial } \\
\text { individuals agree more; } \\
\text { **Those with prior entrepreneurship education }^{\text {agree more; }} \\
\text { *Those want to start own tourism business in the } \\
\text { future agree more. }\end{array}$ \\
\hline $\begin{array}{l}2.6 \text { Being an entrepreneur means } \\
\text { developing a new product or service }\end{array}$ & 2.26 & $\begin{array}{l}\text { *Those want to start own tourism business in the } \\
\text { future agree more. }\end{array}$ \\
\hline $\begin{array}{l}\text { 2.7 Being an entrepreneur means increasing } \\
\text { capital and wealth }\end{array}$ & 2.22 & $\begin{array}{l}{ }^{* *} \text { Those who think they are entrepreneurial } \\
\text { individuals agree more. }\end{array}$ \\
\hline
\end{tabular}

Reliability Statistics (entrepreneurship 'meanings'), Cronbach's Alpha =.552, $\mathrm{N}$ of Items $=7$, Valid cases $=183(88.4 \%)$, Excluded cases $=24(11.6 \%)$, Total $=207$

Perceptions of entrepreneurial inclinations

2.8 I am constantly on the lookout for new 1.88 ways to improve my life

2.9 I feel driven to make a difference in my community, and maybe in the world

2.10 Wherever I have been, I have been a powerful force for constructive change

2.11 I enjoy facing and overcoming obstacles to my ideas

2.12 Nothing is more exciting than seeing my ideas turn into reality

2.13 If I see something that I do not like, I fix 1.89 it

2.14 No matter what the odds, if I believe in something, I will make it happen

2.15 I am always looking for better ways to do things

2.16 If I believe in an idea, no obstacle will 2.03
***Those who think they are entrepreneurial individuals agree more.

$1.96{ }^{* *}$ Those who think they are entrepreneurial individuals agree more.

$2.30 \quad * * *$ Those who think they are entrepreneurial individuals agree more.

$2.05 \quad$ N.S

$1.83 \quad$ N.S

$1.89{ }^{* * *}$ Those want to start own tourism business in the future agree more.

$1.93{ }^{* * *}$ Those who think they are entrepreneurial individuals agree more;

**Those want to start own tourism business in the future agree more;

*Male respondents agree more.

***Those who think they are entrepreneurial individuals agree more.

**Those who think they are entrepreneurial 
prevent me from making it happen

2.17 When I have a problem, I tackle it 2.22 head-on

$2.18 \mathrm{I}$ am great at turning problems into opportunities

2.19 I can spot a good opportunity long 2.16 before others can

2.20 If I see someone in trouble, I help out 2.00 in any way I can individuals agree more.

**Those who think they are entrepreneurial individuals agree more.

N.S

*Those who think they are entrepreneurial individuals agree more.

**Those want to start own tourism business in the future agree more;

**Male respondents agree more.

Reliability Statistics (entrepreneurial inclinations), Cronbach's Alpha =.845, $\mathrm{N}$ of Items = 13, Valid cases $=167(80.7 \%)$, Excluded cases $=40(19.3 \%)$, Total $=207$

Enablers and barriers of starting tourism businesses

2.21 Belief systems within our society can

2.29

hinder youth to start tourism businesses

2.22 Home background can hinder youth to start tourism businesses

2.23 Lack of equipment and machinery can

stop youth to start tourism businesses

2.24 Lack of knowledge of support centres

for entrepreneurs can stop youth to start tourism businesses

2.25 Lack of education and training can hinder youth to start tourism businesses

2.26 Not having business networks can hinder youth to start tourism businesses 2.27 Hardships in obtaining start-up capital can hinder youth to start tourism businesses

2.28 One's gender (male or female) influences the likelihood of starting tourism businesses

2.29 I will have money to start a tourism business

2.38

2.54

2.41

2.35

2.38

2.48

2.82

2.30 I know how to get money to start a small tourism business

2.31 I will have training support to start a 2.53 small tourism business

2.32 The hard work involved in managing 2.54
**Those who think they are entrepreneurial individuals agree more.

*Those who think they are entrepreneurial individuals agree more.

*Those who think they are entrepreneurial individuals agree more.

N.S

**Male respondents agree more.

N.S

N.S

**Those who think they are entrepreneurial individuals agree more.

**Those who think they are entrepreneurial individuals agree more;

**Those with prior entrepreneurship education agree more;

**Those want to start own tourism business in the future agree more.

*Those who think they are entrepreneurial individuals agree more;

**Those want to start own tourism business in the future agree more.

**Those who think they are entrepreneurial individuals agree more;

**Those want to start own tourism business in the future agree more.

***Those who think they are entrepreneurial individuals agree more.

tourism businesses

Reliability Statistics (enablers and barriers), Cronbach's Alpha =.762, $\mathrm{N}$ of Items = 12, Valid cases = $172(83.1 \%)$, Excluded cases $=35(16.9 \%)$, Total $=207$

aMann-Whitney U test significance. N.S, no significant results. ${ }^{*}, \mathrm{p}<0.05 ;{ }^{* *}, \mathrm{p}<0.01$; $^{* *}, \mathrm{p}<0.000$.

${ }^{\mathrm{b}} \mathrm{Questionnaire} \mathrm{were} \mathrm{itemised} \mathrm{along} \mathrm{a} \mathrm{5-point} \mathrm{Likert-type} \mathrm{scale} \mathrm{ranging} \mathrm{from} \mathrm{1,} \mathrm{Strongly} \mathrm{agree;} \mathrm{2,} \mathrm{Agree;} \mathrm{3,}$ Neutral; 4, Disagree; 5, Strongly disagree. 
These results support much of the findings in the previous studies that have been conducted on entrepreneurial inclination in the developing countries. Omerzel (2015), in line with this study's findings, posits the dimensions of entrepreneurial inclination to include risk taking, proactiveness, competitive aggressiveness, autonomy, and customer orientation. Owoseni and Akambi (2010) put forward that venture creation is not likely to take place without motivation.Singh and Singh (2016) report that positive attitude, motivation and perceived behavioral control are the qualifications of entrepreneurial inclination. Previous studies conducted globally, recognised entrepreneurship as a tool for driving a nation's economy (Chell et al., 2016; Gree \& Thurnik, 2003; Iwu et al., 2016; Maziriri \& Madinga, 2016; Maziriri et al., 2017).

Sandhu et al. (2011) outlined the barriers of entrepreneurship to be aversion to stress and hard work, aversion to risk, fear of failure, lack of social networking, lack of resources, and demographic and personal factors. In terms of enablers and barriers of starting tourism businesses, youth members who perceive themselves as entrepreneurial individuals (and mostly want to start their own tourism businesses) agree more to these statements, than those who do not think they are entrepreneurial: 'belief systems within our society can hinder youth to start tourism businesses','home background and lack of capital can hinder youth to start tourism businesses', 'one's gender influences the likelihood of starting tourism businesses', 'I will have money or know how to get money to start a tourism business', 'I will have training support to start a small tourism business', and 'the hard work involved in managing one's business can hinder youth to start tourism businesses'. While these youth members who see themselves as entrepreneurial perceive the significant barriers to entrepreneurial processes in their local community to be in existence, they are still not deterred from thinking they can start their own businesses. They are optimistic that they will have the financial capital and the training support to start their small businesses. As reported earlier, Premand et al. (2016) also agree that entrepreneurship education has the potential to enable youth to gain skills and create their own jobs, and advised policymakers to pay attention to it. Bakare (2015) also call for youth empowerment programs to include entrepreneurial training. In the last section, we conclude our findings and make practical policy recommendations based on our study results.

\section{Conclusion and Recommendations}

The findings from this study show that a significant number of South African youth surveyed recognise the benefits of entrepreneurship towards their nation's socio-economic development and declared their willingness to engage in entrepreneurship. This research however went deeper to compare the youth's perceived level of their own entrepreneurial inclination and their mental attitude towards entrepreneurial dimensions. The youth (those who declare themselves entrepreneurial individuals) tend to have the right mental attitude and motivation to start and sustain businesses. They show the characteristics of being risk takers, goal-getters, innovative, transformational, persistence, strong-minded, visionary, and optimistic. This study therefore recommends that the South African Government, through its national Department of Labour optimise its strategic and operational plans to support these youth members who believe they are entrepreneurial, in terms of providing them with theoretical and practical business education and entrepreneurial skills, especially at the grassroots level. This can be done in collaboration with schools, private sector, and non-governmental organisations to empower youth to realise their dreams of starting and managing their own businesses, and at the same time help to curb the high rate of youth unemployment in South Africa.

\section{References}

Ahmad, S. Z. (2015). Entrepreneurship Education in Tourism and Hospitality Programs. Journal of Hospitality \& Tourism Education, 27(1), 20-29.

Ali, A., Topping, K. J. \& Tariq, R. H. (2009). Entrepreneurial inclinations of prospective teachers. New Horizons in Education, 57(2), 1-16.

Bakare, O. K. (2015). Career prospects of youths and tourism participation in selected host communities in Ekiti State, Nigeria. IFE Psychologia, 23(1), 201-212.

Burger, L., Mahadea, D. \& Neil, C. O. (2004). Perceptions of entrepreneurship as a career option in South Africa: An exploratory study among grade 12 learners. South African Journal of Economic and Management Sciences, 7(1), 187-205. 
Chell, E., Spence, L. J., Perrini, F. \& Harris, J. D. (2016). Social Entrepreneurship and business ethics: Does social equal ethical? Journal of Business Ethics, 133, 619-625.

Chenube, O. O., Saidu, R. F., Omumu, F. C. \& Omomoyesan, M. B. (2011). Assessing the entrepreneurial inclination of university students in Delta State, Nigeria. IFE Psychologia, 19(2), 426-436.

George, D. \& Mallery, P. (2003). SPSS for Windows step by step: A simple guide and reference, 11.0 update (4th Ed.). Boston: Allyn \& Bacon.

Gree, A. \&Thurnik, C. (2003). Firm selection and industry evolution: the post country performance of new firm. Journal of Evolutionary Economics, 4 (4), 243-264.

Gwija, S. A., Eresia-Eke, C. \& Iwu, C. G. (2014). The link between entrepreneurship education and business success: evidence from youth entrepreneurs in South Africa. Journal of Economics, 5(2), 165-174.

IBM Corporation. (2016). IBM SPSS Statistics for Windows, Version 24.0. Armonk, NY: IBM Corp.

Iwu, C. G., Ezeuduji, I. O., Eresia-Eke, C. \&Tengeh, R. (2016). The Entrepreneurial Intention of University Students: The Case of a University of Technology in South Africa. Acta Universitatis Danubius Oeconomica, 12(1), 164-181.

Krueger, N., Reilly, M. D. \& Carsrud, A. L. (2000). Competing models of entrepreneurial intentions. Journal of Business Venturing, 15, 411-432.

Lekoko, M., Rankhumise, E. M. \& Ras, P. (2012). The effectiveness of entrepreneurship education: What matters most? African Journal of Business Management, 6(51), 12023-12033.

Lengyel, G. (2015). Entrepreneurial Inclination and Entrepreneurship in Hungary and in Europe. International Journal of Sociology, 27(4), 3-35.

Mahmoud, M. A., Muharam, F. M. \& Mas'ud, A. (2015). Factors That Influence the Entrepreneurial Intention of Nigerian Postgraduates: Preliminary Analysis and Data Screening. Asian Social Science, 11(4), 180189.

Maziriri, E. T. \& Madinga, N. W. (2016). A qualitative study on the challenges faced by entrepreneurs living with physical disabilities within the Sebokeng Township of South Africa. International Journal of Research in Business Studies and Management, 3(5), 1-13.

Maziriri, E. T., Madinga, W. \& Lose, T. (2017). Entrepreneurial Barriers that are confronted by Entrepreneurs living with Physical Disabilities: A Thematic Analysis. Journal of Economics and Behavioral Studies, 9(1), 27-45.

Minto-Coy, I. \& McNaughton, M. (2016). Barriers to Entrepreneurship and Innovation: An Institutional Analysis of Mobile Banking in Jamaica and Kenya. Social and Economic Studies, 65(2), 107-139.

Mtubatuba Municipality. (2017). Local Economic Development. Retrieved 14 June 2017, from http://mtubatuba.org.za/technical-services/business/

Nchu, R. M., Tengeh, R. K. \& Hassan, S. (2015). High School learner's perception of the efficacy of Entrepreneurship education: The case of selected High schools in the Western Cape, South Africa. The scientific Journal of Theory and Practice of socio-economic Development, 4(8), 507-526.

Olomi, D. R. \& Sinyamule, R. S. (2009). Entrepreneurial Inclinations of Vocational Education Students: A Comparative Study of Male and Female Trainees in Iringa Region, Tanzania. Journal of Enterprising Culture, 17(1), 103-125.

Omerzel, D. G. (2015). The Impact of Entrepreneurial Characteristics and Organisational Culture on Innovativeness in Tourism Firms. Managing Global Transitions, 14(1), 93-110.

Owoseni, 0. O. \& Akambi, P. A. (2010). Entrepreneurial Intentions: A Theoretical Framework. Journal of Management and Corporate Governance, 2(4), 132-148.

Premand, P., Brodmann, S., Almeida, R., Grun, R. \& Barouni, M. (2016). Entrepreneurship Education and Entry into Self-Employment among University Graduates. World Development, 77, 311-327.

Sandhu, M. S., Sidique, S. F. \& Riaz, S. (2011). Entrepreneurship barriers and entrepreneurial inclination among Malaysian postgraduate students. International Journal of Entrepreneurial Behavior\& Research, 17(4), 428-449.

Singh, P. S. \& Singh, H. R. (2016). Entrepreneurial Inclination: a Critical Review. Indian Journal of Research, $5(2), 69-73$.

Steenekamp, A. G., Van der Merwe, S. P. \& Athayde, R. (2011). An investigation into youth entrepreneurship in selected South African secondary schools: An exploratory study. Southern African Business Review, 15(3), 46-75.

Tavakol, T. \& Dennick, R. (2011). Making sense of Cronbach's Alpha. International Journal of Medical Education, 2(1), 53-55. 
Trading Economics. (2017a). South Africa Unemployment Rate. Retrieved 22 June 2017, from https://tradingeconomics.com/south-africa/unemployment-rate

Trading Economics. (2017b). South Africa Youth Unemployment Rate. Retrieved 22 June 2017, from https://tradingeconomics.com/south-africa/youth-unemployment-rate

Veal, A. J. (2011). Research methods for leisure and tourism: a practical guide. $4^{\text {th }}$ ed. Pearson: Essex. 